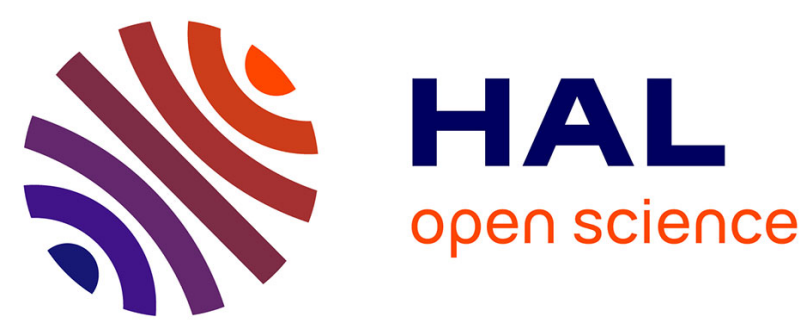

\title{
Validity and reliability of different techniques of neck-shaft angle measurement
}

Aren Joe Bizdikian, Ayman Assi, Ziad Bakouny, Elie Saghbini, G. E. Bakhos, S. Esber, Nour Khalil, Joeffroy Otayek, Joe Ghanimeh, Christophe Sauret, et al.

\section{To cite this version:}

Aren Joe Bizdikian, Ayman Assi, Ziad Bakouny, Elie Saghbini, G. E. Bakhos, et al.. Validity and reliability of different techniques of neck-shaft angle measurement. Clinical Radiology, 2018, 73 (11), pp.984.e1-984.e9. 10.1016/j.crad.2018.06.006 . hal-02197360

\section{HAL Id: hal-02197360 https://hal.science/hal-02197360}

Submitted on 28 Aug 2019

HAL is a multi-disciplinary open access archive for the deposit and dissemination of scientific research documents, whether they are published or not. The documents may come from teaching and research institutions in France or abroad, or from public or private research centers.
L'archive ouverte pluridisciplinaire HAL, est destinée au dépôt et à la diffusion de documents scientifiques de niveau recherche, publiés ou non, émanant des établissements d'enseignement et de recherche français ou étrangers, des laboratoires publics ou privés. 


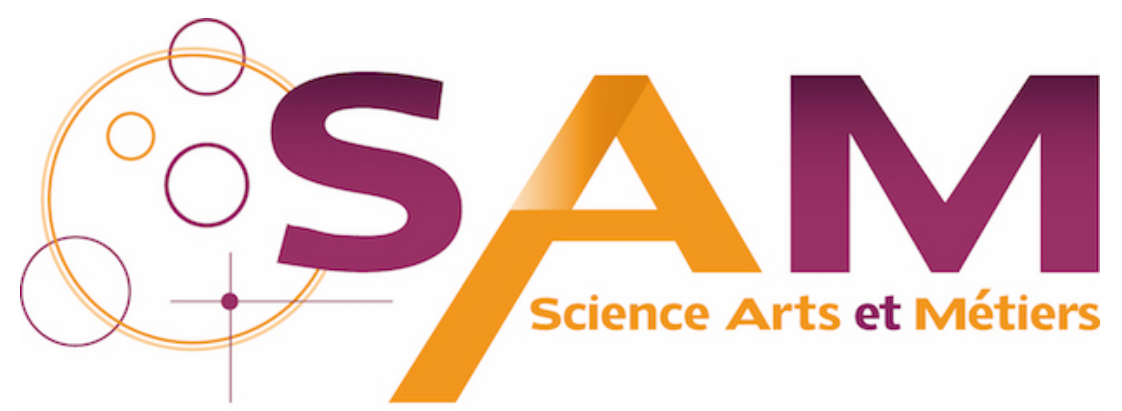

Archive Ouverte - Open Repository

\section{Science Arts \& Métiers (SAM)}

is an open access repository that collects the work of Arts et Métiers ParisTech researchers and makes it freely available over the web where possible.

This is an author-deposited version published in: https://sam.ensam.eu Handle ID: .http://hdl.handle.net/10985/15916

\section{To cite this version :}

Aren Joe BIZDIKIAN, Ayman ASSI, Ziad BAKOUNY, Elie SAGHBINI, G. E. BAKHOS, S. ESBER, Nour KHALIL, Joeffroy OTAYEK, Joe GHANIMEH, Christophe SAURET, Waffa SKALLI, Ismat B. GHANEM - Validity and reliability of different techniques of neck-shaft angle measurement Clinical Radiology - Vol. 73, n¹1, p.984.e1-984.e9-2018 


\title{
Validity and reliability of different techniques of neck-shaft angle measurement
}

\author{
A.J. Bizdikian ${ }^{\text {a }}$, A. Assi ${ }^{\text {a, b, * }}{ }^{\text {Z. Bakouny }}{ }^{\text {a }}$, F. Yared ${ }^{\text {a }}$, E. Saghbini ${ }^{\text {a }}$, \\ G.E. Bakhos ${ }^{\text {a }}$, S. Esber ${ }^{\text {a }}$, N. Khalil ${ }^{\text {a }}$, J. Otayek ${ }^{a}$, J. Ghanimeh ${ }^{\text {a }}$, C. Sauret ${ }^{b}$, \\ W. Skalli ${ }^{\mathrm{b}}$, I. Ghanem ${ }^{\mathrm{a}, \mathrm{c}}$ \\ ${ }^{a}$ Laboratory of Biomechanics and Medical Imaging, Faculty of Medicine, University of Saint-Joseph, Beirut, Lebanon \\ ${ }^{\mathrm{b}}$ Institut de Biomécanique Humaine Georges Charpak, Arts et Métiers ParisTech, Paris, France \\ ${ }^{\mathrm{c}}$ Hôtel-Dieu de France Hospital, University of Saint-Joseph, Beirut, Lebanon
}

AIM: To determine a valid and reliable neck-shaft angle (NSA) measurement method while rotating the pelvises in increments of $5^{\circ}$ in order to simulate patient malpositioning.

MATERIALS AND METHODS: CT images of 17 patients were used to produce digitally reconstructed radiographs in frontal and lateral views and three-dimensional (3D)-reconstructions of the femurs, considered to be the reference standard. Malpositioning was simulated by axially rotating the frontal radiographs from $0^{\circ}$ to $20^{\circ}$. Three operators measured in two-dimensions the NSA using four different methods, three times each, at each axial rotation (AR) position. Method 1 (femoral neck axis drawn by joining the centre of the femoral head $(\mathrm{CFH})$ to the median of the femoral neck base; femoral diaphysis axis drawn by joining the median of two lines passing through the medial and lateral edges of the femoral axis below the lesser trochanter) and method 2 (femoral axis taken as the median of a triangle passing through base of femoral neck and medial and lateral head-neck junction; femoral diaphysis as previous) were described for the first time; method 3 was based on a previous study; method 4 was a free-hand technique. Reliability, validity, and global uncertainty were assessed.

RESULTS: Method 1 showed the best reliability and validity. The global uncertainty also showed minimal values for method 1 , ranging from $7.4^{\circ}$ to $14.3^{\circ}$ across AR positions.

CONCLUSION: Method 1, based on locating the CFH, was the most reliable and valid method and should be considered as a standardised two-dimensional NSA measurement method for clinical application.

\section{Introduction}

The neck-shaft angle (NSA), also known as the caput-collum-diaphyseal angle, is the angle formed by the intersection of a line passing through the femoral shaft and a line passing through the femoral head and neck. It is an important parameter to assess the geometry of the proximal femur, as well as pathologies in adult and paediatric 
patients, such as hip dysplasia, ${ }^{2}$ osteoarthritis, ${ }^{3}$ and the risk of femoral neck fracture. ${ }^{3,4}$ NSA is also related to other hip parameters, including femoral head offset, femoral neck length, ${ }^{5}$ and acetabular version, ${ }^{6}$ and is commonly used in pre-surgical planning of the proximal femur.

Although there are a variety of methods for the measurement of NSA on an anteroposterior radiograph, there is currently no consensus on the optimal technique to use. Some methods require radiographs of only the proximal femur, while others require radiographs of the entire femur. ${ }^{7}$ The latter are often impractical as frontal hip radiographs generally only include the proximal femur. Furthermore, the accuracy of NSA measurements depends on the correct positioning of the patient during X-ray acquisition, ${ }^{7}$ and particularly, on the axial rotation (AR) of the hip. 8,9 This issue is very common in pelvic radiographs where spinal deformities are known to affect pelvic $A R,{ }^{10}$ and consequently, hip and proximal femur parameters.

A recent literature review ${ }^{7}$ reported that NSA measurement is sensitive to hip rotation and that there is an impairment in the reproducibility of NSA measurement methods due to the lack of consistency in the definition of the methods. Therefore, a consensus on a specific technique should take into account both the reliability of the method and its indifference to pelvic AR. Thus, the aim of the present study was to evaluate the validity (sensitivity to AR position) and reliability of different methods of NSA measurement on commonly used anteroposterior hip radiographs, while simulating patient AR malpositioning.

\section{Materials and methods}

\section{Sample}

Helical pelvic computed tomography (CT) images of 17 patients, including pelvises and proximal femurs (section thickness: $0.6 \mathrm{~mm}$, resolution: $512 \times 512$ pixels, pixel spacing: $0.7675 \mathrm{~mm}$ ) were extracted from the database of the radiology department of the hospital. All patients had undergone CT in order to investigate pain unrelated to the hip. Only normal hips were considered in this study, with no deformities of the femoral head, femoral neck, or femoral diaphysis. Nine adult patients (four male, five female) with an average age of 55.6 years old (SD: 24.5), ranging from 22 to 80 years old, and eight paediatric patients (five male, three female) with an average age of 12 years old (SD: 2.2), ranging from 9 to 15 years old were included. The design of the present study was approved by the institutional review board.

Frontal and lateral digitally reconstructed radiographs (DRRs) were simulated from each CT dataset in a DICOM format, with squared pixels (pixel spacing $=0.141 \mathrm{~mm}$ ), using a specific software (Arts et Métiers ParisTech, Paris, France). This technique, which has already been used for the pelvis and the rib cage, ${ }^{11,12}$ enables the simulation of the AR of the CT volume:

The generation of frontal and lateral DRRs is based on linear scanning by the X-ray beams from the top to the bottom of the CT volume with cylindrical projections: a collimator is simulated to avoid vertical diversion of the Xrays and to allow only horizontal propagation. In order to measure exact lengths on the radiographs, the horizontal enlargement was corrected by applying a scaling factor on the image.

Radiographic rotation was mimicked by rotating the CT volume around the vertical axis. Thus, five frontal DRRs were generated from each CT series, while introducing an AR from $0^{\circ}$ to $20^{\circ}$ with increments of $5^{\circ}$ (Fig 1 ). In order to assess the effect of rotational malpositioning in general, the two hips from each patient, at each DRR, were included in this analysis, without distinguishing internal rotation from external rotation between the two hips of each subject.

\section{Radiological parameters}

The SterEOS 2D software (version 1.5.1; EOS Imaging, Paris, France) was used in order to digitally measure the NSA in two dimensions. This toolbox allows the user to measure and draw: lines between two points showing their midpoint, perfect horizontal or vertical lines, perpendiculars, an angle between two lines, as well as circles modifiable by their diameters and the centres of which are automatically determined. The NSA was measured bilaterally in two dimensions, on each frontal radiograph, using four different methods based on the determination of the angle between the neck axis and the shaft axis. Two methods, which were developed for the purpose of this study, were measured along with two previously described methods. ${ }^{13-15}$ The aforementioned methods were chosen as they require radiographs of only the proximal femur.

\section{Method 1 (Fig 2a)}

Neck axis: a circle was drawn by placing three points on the contour of the femoral head, thereby automatically determining its centre $(A)$. The midpoint of the base of the femoral neck was identified (B). The neck axis was then drawn by joining $A$ and $B$.

Shaft axis: a horizontal line was drawn passing through the caudal end of the lesser trochanter between the edges of the lateral and medial cortices of the femoral diaphysis. The midpoint of this line was determined (C). A second horizontal line was drawn more caudally on the diaphysis and its midpoint was determined (D). The shaft axis was then drawn by joining $C$ and $D$.

\section{Method 2 (Fig 2b)}

Neck axis: a line extending from the greater trochanter at its junction with the femoral neck to the upper head-neck junction was drawn; a second line extending from the lesser trochanter at its junction with the femoral neck to the lower head-neck junction was drawn. The point at which the two lines intersect was determined $(A)$. The midpoint of the base of the femoral neck was identified (B). The neck axis was then drawn by joining $A$ and $B$.

Shaft axis: identical to method 1. 


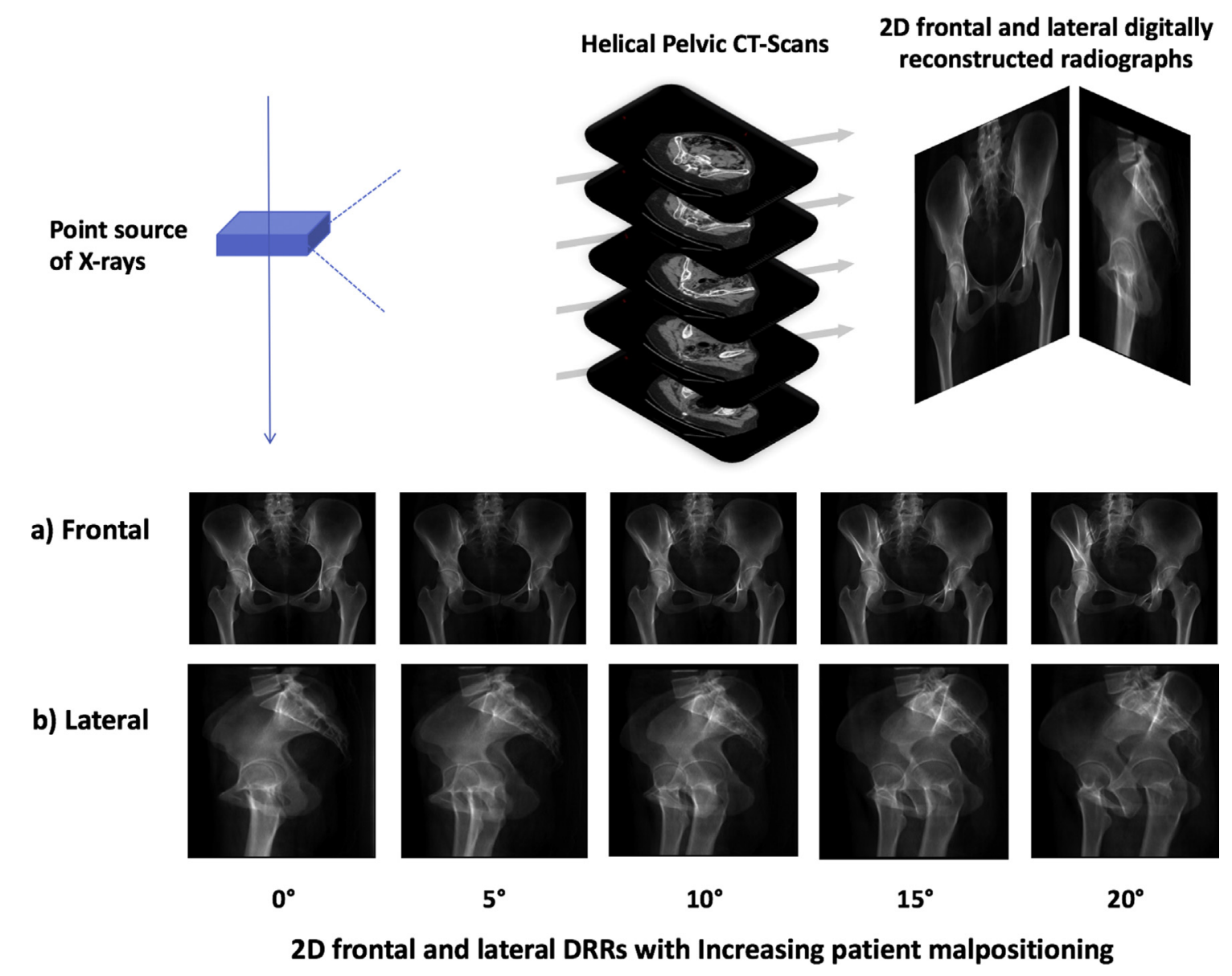

Figure 1 Two-dimensional (a) frontal and (b) lateral digitally reconstructed radiographs of the pelvis and proximal femur from helical pelvic CT images with increasing pelvic AR in increments of $5^{\circ}$.

\section{Method $3^{15}$ (Fig 2c)}

Neck axis: The largest mediolateral chord, defining the diameter of the femoral head, was drawn and its midpoint was defined (A). The narrowest points on the neck edges were joined and their midpoint determined (B). The neck axis was then drawn by joining $A$ and $B$.

Shaft axis: a line was drawn caudal to the lesser trochanter between the edges of the lateral and medial cortices of the femoral diaphysis. The midpoint of this line was determined (C). A second parallel line was drawn more caudally on the diaphysis and its midpoint was determined (D). The shaft axis was then drawn by joining $C$ and $D$.

\section{Method 4 is a free-hand technique ${ }^{13,14}$ (Fig 2d)}

Neck axis: The axis of the neck is a line estimated by the user and passing through the centre of the circle defining the femoral head.

Shaft axis: The axis of the shaft is an axis passing through the femoral diaphysis and estimated by the user.

In order to evaluate the validity of the four twodimensional (2D) methods of NSA measurement, a 3D reconstruction of the patients' proximal femurs, at $0^{\circ}$ of $A R$, was performed (Fig 2e). This 3D reconstruction method is based on a previously described technique using specific anatomical landmarks on both frontal and lateral radiographs of the femur, $, 11,16-19$ and relies on parametric models and statistical inferences. ${ }^{18}$ The validity and reliability of this technique had previously been assessed. ${ }^{17,20,21}$ The 3D reconstruction was performed using specific software (Arts et Métiers ParisTech). The NSA is then measured in $3 \mathrm{D}$ as the angle between the least square axes of the femoral neck and the diaphysis mesh regions ${ }^{17}$ and used as the reference standard reference for the validity assessment of the four previously described 2D NSA measurement methods.

\section{Data processing}

Three operators (medical interns) were thoroughly trained on the methods of measurement. The four different methods were measured on each frontal DRR, at each pelvic AR position $\left(0^{\circ}, 5^{\circ}, 10^{\circ}, 15^{\circ}, 20^{\circ}\right)$, three times by each operator, in order to assess intra and interoperator reliability. Repeated measurements were separated by 2-week intervals. Moreover, the four methods were measured separately each time in order to avoid visual memory of the axes by the operators. A fourth trained operator (medical intern) reconstructed all the hips in $3 \mathrm{D}$, at $0^{\circ}$ of $\mathrm{AR}$. 


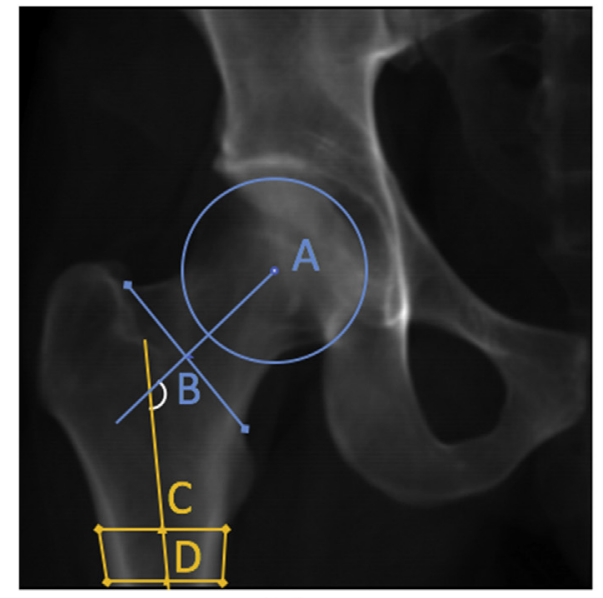

(a)

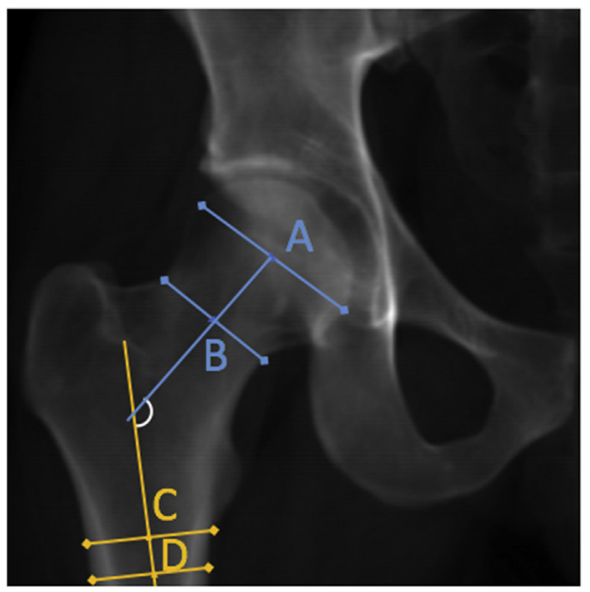

(c)

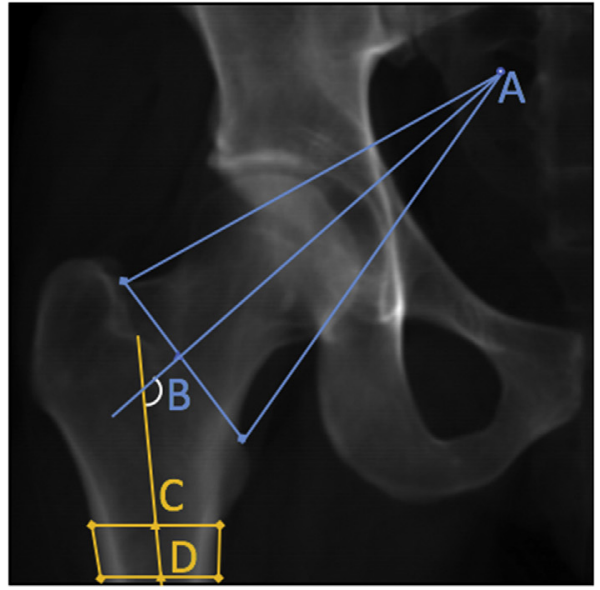

(b)

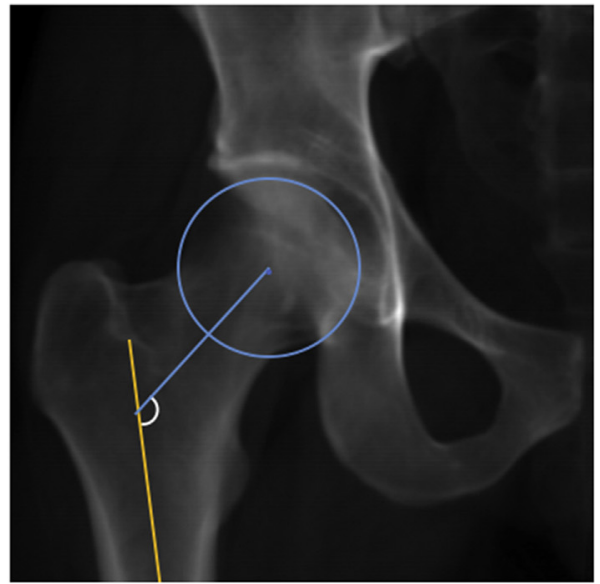

(d)

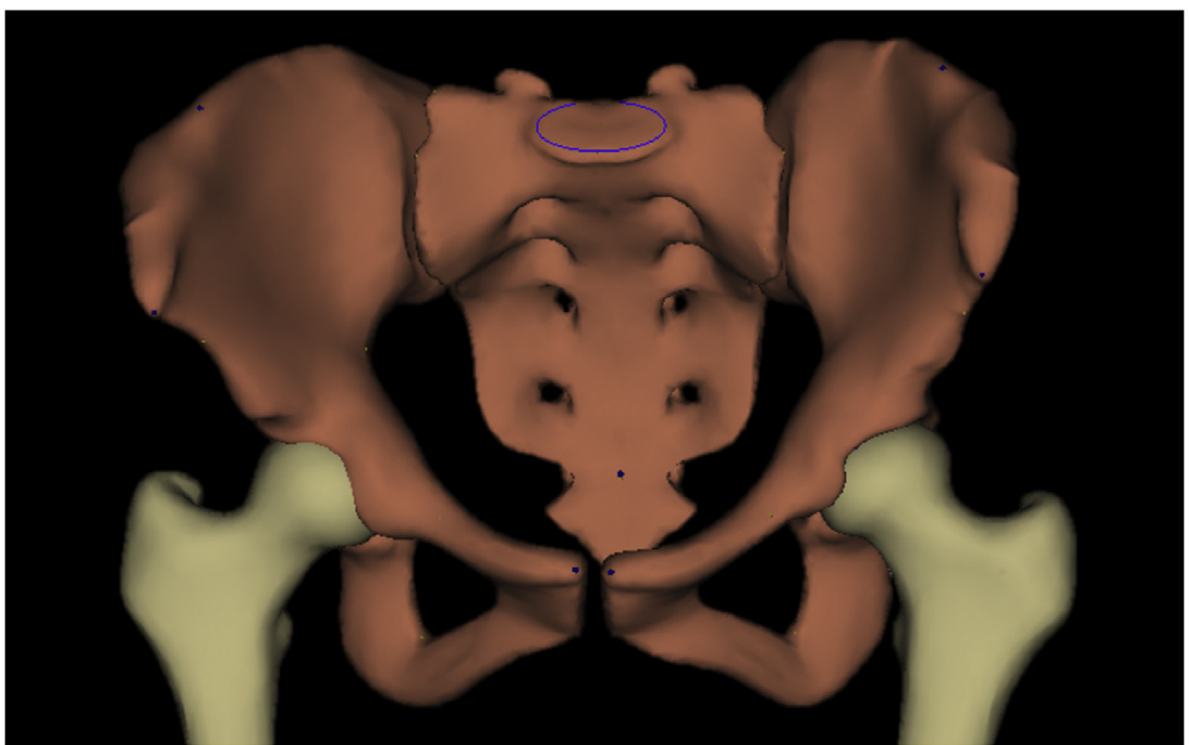

(e)

Figure 2 (a) Three-dimensional model of the pelvis and proximal femurs and the four different 2D methods of NSA measurement: (b) method 1; (c) method 2; (d) method 3 (Wilson et al. 2011); (e) method 4 (Houston \& Zaleski 1967, Chung et al. 2010). 


\section{Data analysis}

\section{Reliability}

In order to assess the global intra- and interobserver agreement, the intraclass correlation coefficient (ICC), $(2, \mathrm{k})$ model, was calculated for each method: ICC $>0.80$ indicates very high reliability, $0.60-0.80$ moderately high reliability, $0.40-0.59$ moderate reliability and $<0.40$ low reliability. ${ }^{22,23}$ The reproducibility variance $\left(S_{R}\right)$, that includes both intra- and inter-rater variability, was calculated for each parameter, according to the guidelines of the ISO 57252 standard. ${ }^{24}$ The $95 \%$ confidence interval $(95 \% \mathrm{CI})$ was then calculated as $2 \mathrm{~S}_{\mathrm{R}}$.

\section{Validity}

In order to evaluate the validity of the different 2D NSA measurement methods, the bias $(\delta)$ on the measurement methods, created by both the errors caused by the $2 \mathrm{D}$ technique of measurement itself and the presence of pelvic AR malpositioning, was calculated as the difference between the mean value of all of the measurements (three operators, three measurements each) and the measurement obtained by the 3D reconstructions of the hips in the absence of AR. Means and standard deviations (SD) of the bias values were then calculated. Bland-Altman graphs were plotted displaying the dispersion of the bias values with the means and the 2 SD of the respective NSA measurement methods, for the different NSA measurement methods, at different AR positions (Fig 3).

The global uncertainty $( \pm \varepsilon)$, the resultant of the systematic (trueness) and random (precision) errors including both the validity and the reliability errors, was then calculated as the sum of the absolute value of the bias $(\delta)$ and the $95 \% \mathrm{CI}$ as previously described by Ghostine et al. ${ }^{11}$ This represents the most unfavourable definition of global uncertainty: $\varepsilon=|\delta|+2 \mathrm{~S}_{\mathrm{R}}$.

Calculations and statistics were performed using MATLAB (Mathworks Inc., Natick, MA, USA), Xlstat (Addinsoft, Paris, France), and SPSS (IBM, NY, USA). The level of significance for statistical tests was set at 0.05 .

\section{Results}

\section{Reliability}

The values of the $S_{R}$, bias and ICC of the four 2D NSA measurement methods were displayed in Table 1. Method 1 showed the highest ICC values, ranging from 0.92 to 0.96 . Method 4, however, showed the lowest ICC values, ranging from 0.71 to 0.98 . Moreover, method 1 showed the lowest reproducibility coefficient across all AR positions: $S_{R}$ increased from $1.76^{\circ}$ at $0^{\circ}$ of AR to $2.35^{\circ}$ at $20^{\circ}$ of AR; however, in the case of method 4 , it increased from $3.00^{\circ}$ at $0^{\circ}$ of AR to $3.26^{\circ}$ at $15^{\circ}$ of AR, and decreased at $20^{\circ}$ of AR, reaching its minimum of $2.52^{\circ}$.

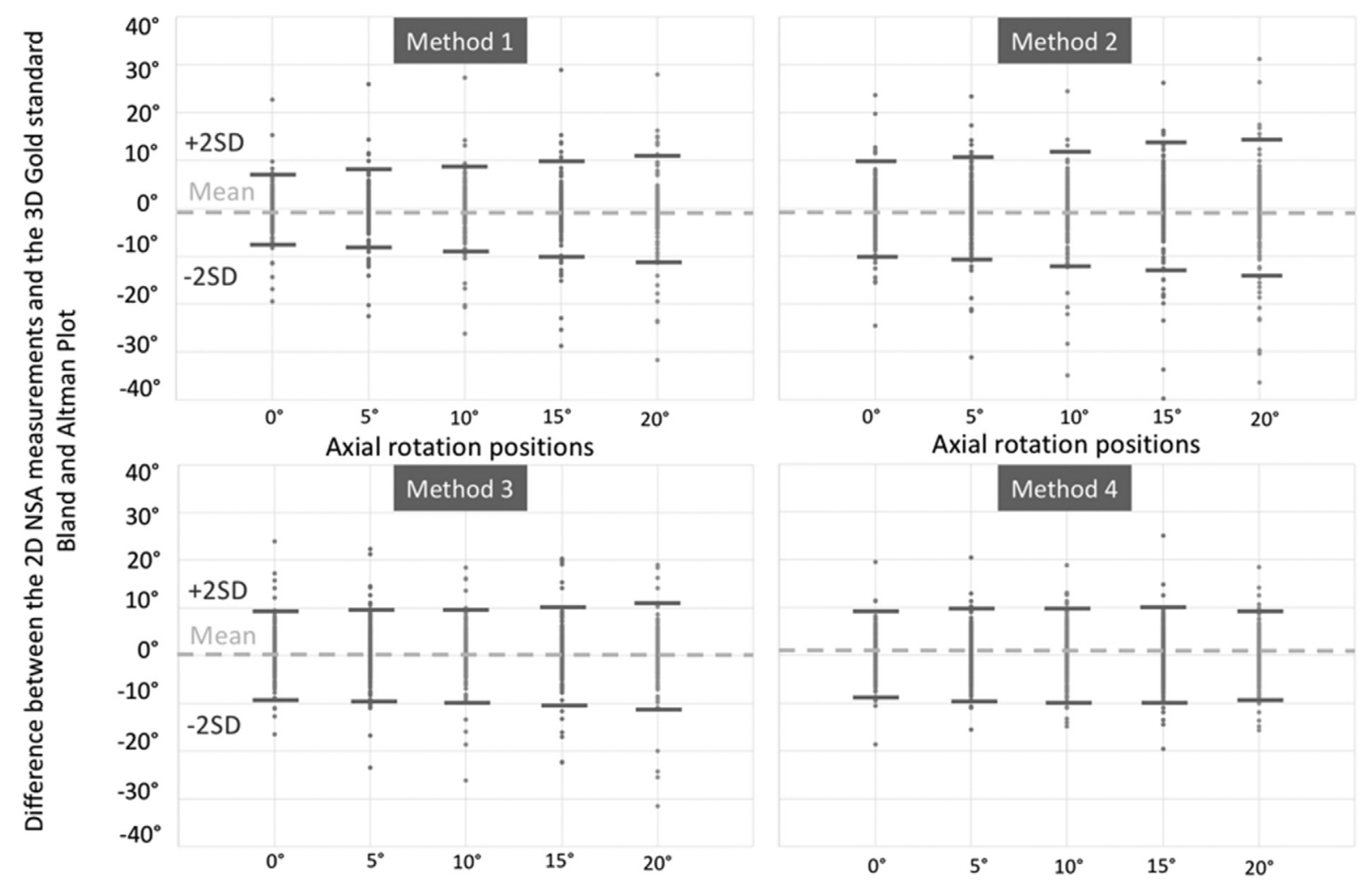

Figure 3 Bland-Altman plots displaying the differences between the 2D NSA measurement methods (three operators, three times each for all 17 patients) and the 3D reference standard, at different AR positions. The mean and 2 SD of these differences are displayed. 
Table 1

Bias to the three-dimensional reference $( \pm S D)$, repeatability variance $\left(S_{R}\right)$ and intraclass correlation coefficient (ICC) calculated for the different neckshaft angle measurement methods at different pelvic axial rotation (AR) positions.

\begin{tabular}{lllll}
\hline Methods & AR & Mean bias \pm SD & $S_{\mathrm{R}}$ & ICC \\
\hline Method 1 & $0^{\circ}$ & $3.9 \pm 3.3^{\circ}$ & $1.76^{\circ}$ & 0.94 \\
& $5^{\circ}$ & $4.9 \pm 3.5^{\circ}$ & $2.24^{\circ}$ & 0.92 \\
& $10^{\circ}$ & $6.2 \pm 4.4^{\circ}$ & $2.10^{\circ}$ & 0.95 \\
& $15^{\circ}$ & $7.7 \pm 5.0^{\circ}$ & $2.09^{\circ}$ & 0.96 \\
Method 2 & $20^{\circ}$ & $9.6 \pm 5.8^{\circ}$ & $2.35^{\circ}$ & 0.96 \\
& $0^{\circ}$ & $4.7 \pm 4.0^{\circ}$ & $3.06^{\circ}$ & 0.84 \\
& $5^{\circ}$ & $5.6 \pm 4.5^{\circ}$ & $3.51^{\circ}$ & 0.85 \\
& $10^{\circ}$ & $7.1 \pm 5.7^{\circ}$ & $3.09^{\circ}$ & 0.92 \\
Method 3 & $15^{\circ}$ & $8.7 \pm 6.2^{\circ}$ & $3.31^{\circ}$ & 0.93 \\
& $20^{\circ}$ & $10.3 \pm 7.2^{\circ}$ & $3.87^{\circ}$ & 0.93 \\
& $0^{\circ}$ & $4.2 \pm 3.7^{\circ}$ & $2.72^{\circ}$ & 0.98 \\
& $5^{\circ}$ & $4.1 \pm 3.0^{\circ}$ & $3.37^{\circ}$ & 0.77 \\
& $10^{\circ}$ & $4.8 \pm 3.3^{\circ}$ & $2.99^{\circ}$ & 0.86 \\
& $15^{\circ}$ & $5.4 \pm 3.6^{\circ}$ & $3.16^{\circ}$ & 0.86 \\
Method 4 & $20^{\circ}$ & $7.0 \pm 4.2^{\circ}$ & $3.46^{\circ}$ & 0.89 \\
& $0^{\circ}$ & $4.8 \pm 2.2^{\circ}$ & $3.00^{\circ}$ & 0.71 \\
& $5^{\circ}$ & $4.6 \pm 2.9^{\circ}$ & $3.11^{\circ}$ & 0.80 \\
& $10^{\circ}$ & $5.9 \pm 3.3^{\circ}$ & $3.20^{\circ}$ & 0.78 \\
& $15^{\circ}$ & $7.1 \pm 4.0^{\circ}$ & $3.26^{\circ}$ & 0.79 \\
& $20^{\circ}$ & $7.7 \pm 3.9^{\circ}$ & $2.52^{\circ}$ & 0.98 \\
\hline
\end{tabular}

\section{Validity}

The bias relative to the $3 \mathrm{D}$ reference was highest in method 2, ranging from $4.7^{\circ}$ to $10.3^{\circ}$. Method 3 , however, showed the lowest bias, ranging from $4.1^{\circ}$ to $7.0^{\circ}$. The Bland-Altman graphs were plotted in Fig 3 for each measurement method at each AR position. The global uncertainty $(\varepsilon)$ was presented in Fig 4. Method 1 showed the lowest overall values, increasing from $7.4^{\circ}$ at $0^{\circ}$ of $A R$ to $14.3^{\circ}$ at $20^{\circ}$ of AR. Method 2 showed the highest values across all AR positions, increasing from $10.9^{\circ}$ at $0^{\circ}$ of $A R$ to $18.0^{\circ}$ at $20^{\circ}$ of AR. Method 3 showed values varying between $9.6^{\circ}$ at $0^{\circ}$ of AR and $13.9^{\circ}$ at $20^{\circ}$ of AR. Method 4 showed values varying between $10.8^{\circ}$ and $13.6^{\circ}$.

\section{Discussion}

NSA is a commonly measured parameter on pelvic radiographs, allowing the assessment of pathologies related to the hip, such as coxa vara and coxa valga, and is therefore predictive of diseases, such as osteoarthritis of the hip joint. Nevertheless, there is no consensus on the best method to use when it comes to the measurement of this parameter. Furthermore, patient malpositioning during X-ray acquisition is frequent, and could affect this measurement. Although previous studies have assessed either the repeatability of NSA measurement techniques ${ }^{2,14,15,25-32}$ or the effect of rotation on the measurement of NSA, ${ }^{8,30}$ none have studied both aspects in order to conclude on the best measurement method. This study evaluated the validity and repeatability of four NSA 2D measurement methods using frontal DRRs while simulating pelvic AR malpositioning at different degrees and comparing it to the $3 \mathrm{D}$ reference value.
Previous studies have tested the repeatability of NSA measurement methods using the intraclass correlation coefficient (ICC). ${ }^{2,14,15,26,29,31-33}$ In the present study, the $S_{R}$ was used as per the ISO 5725-2 standard, ${ }^{24}$ in addition to the ICC. The $S_{R}$ is an important parameter as it provides an estimate for a margin of error due to the repeatability (calculated in ${ }^{\circ}$ ), in contrast to the ICC, which only represents a coefficient. In fact, as demonstrated by Bland-Altman, correlation coefficients have been shown to be less than optimal in reliability studies, as this measure only evaluates the relation between different methods and not the agreement ${ }^{34}$; however, these two parameters are generally inversely related: the lower the $S_{R}$, the higher the ICC, and conversely. The ICC was mainly calculated in order to allow for comparability of the present study with the literature.

The ICC values obtained in this study were generally high $(>0.70)$ and were similar to values presented in previous studies. ${ }^{2,14,32}$ Method 1 showed very high reliability (ICC between 0.92 and 0.96 ), while method 4 had the lowest reliability with a minimum of 0.71 . Similarly, method 1 showed the overall lowest $S_{R}$ values (between $1.76^{\circ}$ and $2.35^{\circ}$ ), and method 4 the highest (between $2.52^{\circ}$ and $3.26^{\circ}$ ).

Therefore, method 1 was deemed to be the most repeatable. This may be due to the fact that it relied on a set of anatomical landmarks that may be more easily identifiable than with the other techniques. In fact, the axis of the diaphysis is identical in methods 1 and 2 , and is very similar to the one measured in method 3; however, neck axis placement varied between these methods. This suggests that techniques that rely on pinpointing the centre of the femoral head, such as in method 1 , might be more repeatable and less error-prone than other techniques for the identification of the femoral neck axis. In addition, method 4 , showed the lowest ICC and the highest $S_{R}$, and was considered the least repeatable. This result was somewhat expected as this method did not rely on any anatomical landmark and was therefore subjected to more inter- and intra-observer variability.

Although reliability represents the inter- and intraoperator variation of the different NSA measurement methods, validity aims to assess the gap between a certain measurement method and a reference standard. In the present study, validity was evaluated using the bias as the difference between the values obtained by each 2D method and the values obtained by the 3D reference method.

The Bland-Altman graphs (Fig 3) showed that the dispersion of the bias values of the NSA measurement methods increased with increasing AR, which may have been caused by a decrease in visibility of the required anatomical features when AR increased. In fact, when the AR increased, some anatomical landmarks used to measure the NSA in methods 1,2 , and 3 tended to be superimposed with other bony structures. Methods 1,3 , and 4 showed a low dispersion of bias values. In method 4 , the dispersion increased only slightly with increasing AR, leading to the least amount of dispersion on the Bland-Altman graph. This may be explained by the fact that the operators might have been able to better assess the overall anatomy of the 


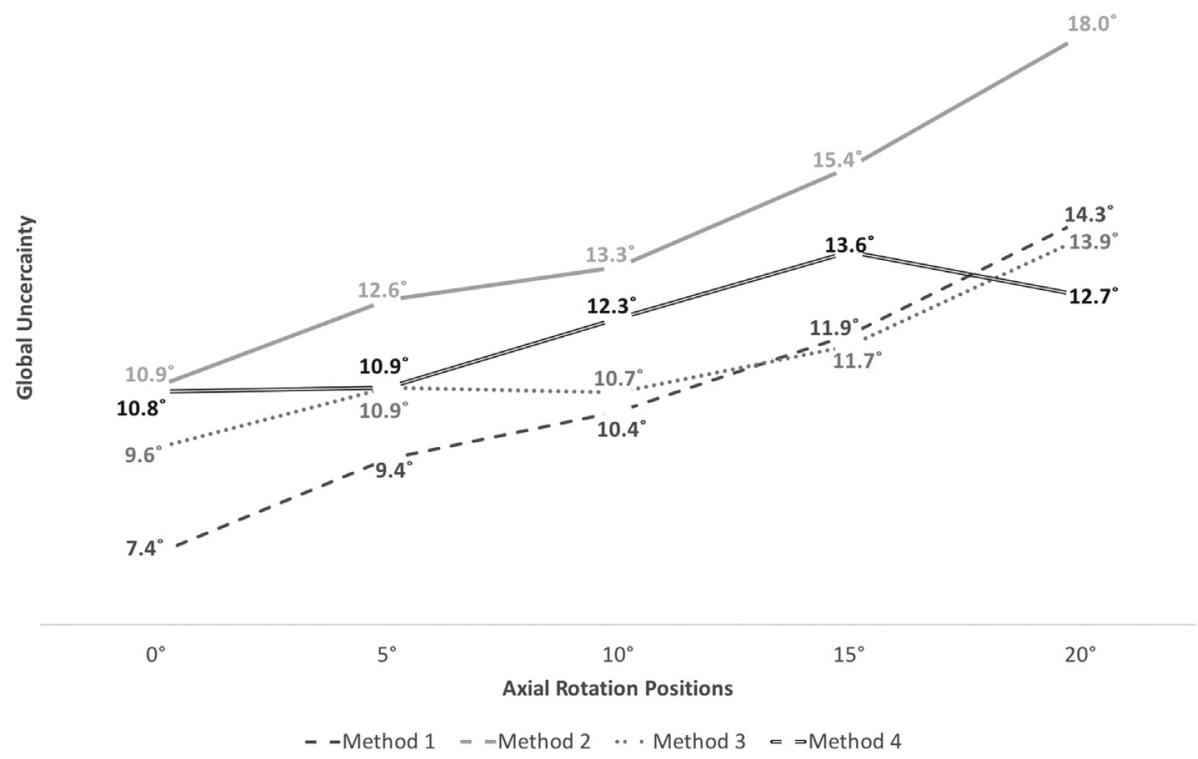

Figure 4 Global uncertainty $(\varepsilon)$ for each NSA measurement method at different increments of pelvic AR malpositioning.

proximal femur by visual assessment when not bound to a specific set of anatomical landmarks which may be hidden during patient malpositioning. In fact, when analysing the NSA in patients with hips with an abnormal anatomy, preference of method 4 over other methods may be understandable, as it does not rely on specific anatomical landmarks that may be modified and therefore alter the measurement of the NSA in patients with abnormal hips.

Moreover, method 2 showed the highest dispersion on the Band-Altman graph. This suggests that the visibility of the medial and lateral extremities of the femoral neck, on which method 2 relies, may be highly affected by patient malpositioning. Furthermore, the increase of bias with AR malpositioning may also be related to the fact that the angle between the two axes defining the NSA is a projected angle of a 3D structure on a 2D frontal radiograph. It is known that when axially rotating these two axes, the projected angle in the frontal plane will be affected and will differ from the initial angle calculated without AR malpositioning; however, when the angle between the two axes is calculated in $3 \mathrm{D}$, the value of this angle will not be affected by AR malpositioning. A mathematical simulation of this situation is presented in Fig 5.

As this study relied on NSA measurement methods on only hip radiographs, as opposed to full-length femoral radiographs, another source of potential error in the measurements might have been influenced by the amount of exposed femoral diaphysis.

In sum, the global uncertainty $(\varepsilon)$, including both errors of reliability and validity showed that method 1 had the lowest uncertainty among all methods. While considering the results pertaining to this calculation, as well as the reliability and validity studies, method 1 was considered as the preferable method to use in the measurement of the NSA. This may be due to the fact that method 1 relied on a set of anatomic landmarks that could have been better conserved with increasing AR, and therefore more reliable in their determination.
The minimal clinically significant variation for NSA measurement has been previously shown to be $5 .{ }^{15}$ In the present study, this threshold was reached at $5^{\circ}$ of AR for method 2 (bias of $5.4^{\circ}$ ), $10^{\circ}$ of AR for methods 1 and 4 (biases of $6.2^{\circ}$ and $5.9^{\circ}$ respectively), and $15^{\circ}$ of AR for method 3 (bias of $5.4^{\circ}$ ). It is therefore recommended that all $\mathrm{X}$-rays be visually checked for malpositioning before measuring the NSA, since for most methods, even slight rotational malpositioning can significantly alter the value of the NSA. In order to evaluate the error in NSA measurement due to rotational malpositioning, only the rotation of the femur should be taken into account. In fact, patients may present malpositioning of only the proximal femur with no rotation of the pelvis, and thus pelvic rotation estimation methods may be of little use in this case. As Zhang et al. showed that the lesser trochanter may be used in order to evaluate the rotation of the femur, ${ }^{35}$ this technique may be used in order to visually assess whether the femur is properly oriented: when the lesser trochanter is hidden behind the femoral diaphysis, then the femur is probably in excessive internal rotation; when the lesser trochanter is completely visible, then it is probably in excessive external rotation (Fig 6). In such cases, the clinician should take into account the potential errors on NSA measurement that could be due to patient malpositioning during X-ray acquisition.

A viable alternative, when possible, may be the use of 3D reconstruction techniques based on low dose bi-planar Xrays in order to calculate the NSA. This technique has been shown to be only mildly affected by rotational bias. ${ }^{11}$

In conclusion, the determination of a standardised and repeatable method for the measurement of the NSA is essential in order to decrease the heterogeneity associated with NSA measurement. In the present study, the method based on the identification of the exact location of the centre of the femoral head in order to later draw the femoral neck axis (method 1) showed the highest repeatability as well as the lowest bias and global uncertainty. Method 1 


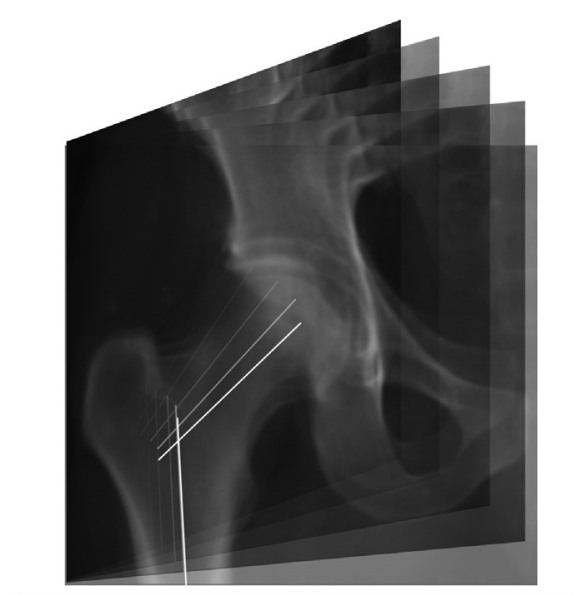

Simulation of projection of the axes defining NSA on the frontal radiograph while axially rotating the femur
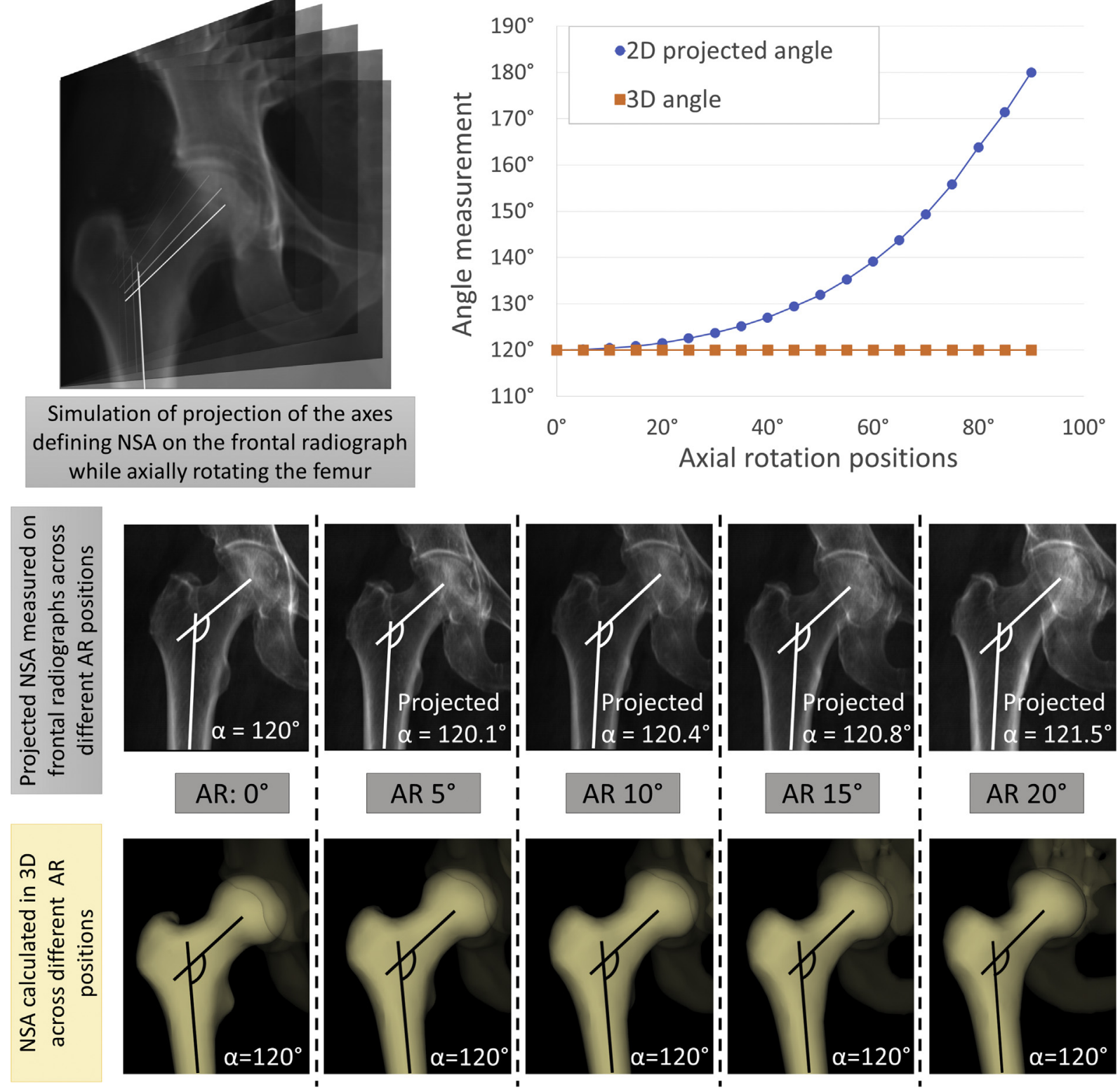

Figure 5 Simulation of NSA calculations as a 2D projection on the frontal plane of the 3D angle with increasing ARs.

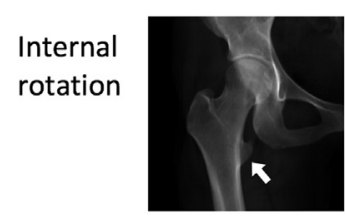

$0^{\circ}$

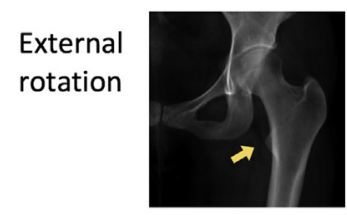

$0^{\circ}$

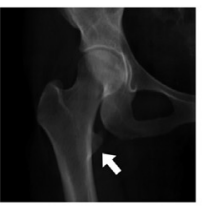

$5^{\circ}$

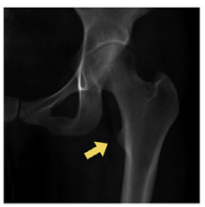

$5^{\circ}$

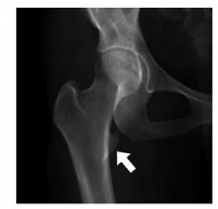

$10^{\circ}$

(a)

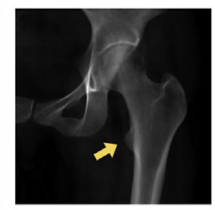

$10^{\circ}$

(b)

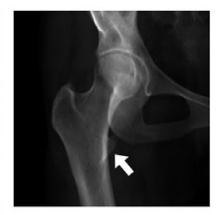

$15^{\circ}$

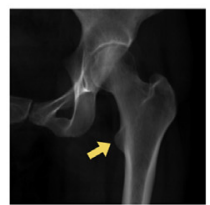

$15^{\circ}$

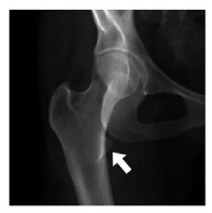

$20^{\circ}$

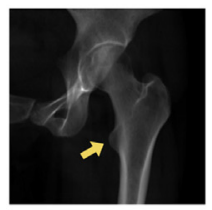

$20^{\circ}$

Figure 6 Visibility of the lesser trochanter in relation to the femoral diaphysis with increasing (a) internal rotation and (b) external rotation of the femur. 
should therefore be considered as a standardised method for the 2D measurement of the NSA and used in clinical application in the absence of $3 \mathrm{D}$ reconstruction techniques.

A limitation of this study may be the fact that only normal hips were evaluated, and that the same measured parameters on pathological or deformed hips may not be as reliable or repeatable as in normal hips. Moreover, this study only addressed rotation of the pelvis in the axial plane, and not in coronal and sagittal planes.

\section{References}

1. Wright D, Whyne C, Hardisty M, et al. Functional and anatomic orientation of the femoral head. Clin Orthop Relat Res 2011;469(9):2583-9. https://doi.org/10.1007/s11999-010-1754-1.

2. Bouttier R, Morvan J, Mazieres B, et al. Reproducibility of radiographic hip measurements in adults. Jt Bone Spine 2013;80(1):52-6. https:// doi.org/10.1016/j.jbspin.2012.02.002.

3. Teo PC, Kassim AYM, Thevarajan KA. 45-degree radiographic method for measuring the neck shaft angle and anteversion of the femur: a pilot study. J Orthop Surg 2013;21(3):340-6.

4. Ripamonti C, Lisi L, Avella M. Femoral neck shaft angle width is associated with hip-fracture risk in males but not independently of femoral neck bone density. Br J Radiol 2014;87(1037), https://doi.org/10.1259/ bjr.20130358.

5. Clark J, Freeman M, Witham D. The relationship of neck orientation to the shape of the proximal femur. J Arthroplasty 1987;2(2):99-109.

6. Buller LT, Rosneck J, Monaco FM, et al. Relationship between proximal femoral and acetabular alignment in normal hip joints using 3-dimensional computed tomography. Am JSports Med 2012;40(2):367-75. https://doi.org/ $10.1177 / 0363546511424390$.

7. Boese CK, Dargel J, Oppermann J, et al. The femoral neck-shaft angle on plain radiographs: a systematic review. Skeletal Radiol 2016;45(1): 19-28. https://doi.org/10.1007/s00256-015-2236-z.

8. Kay RM, Jaki KA, Skaggs DL. The effect of femoral rotation on the projected femoral neck-shaft angle. J Pediatr Orthop 2000;20(6):736-9.

9. Lechler P, Frink M, Gulati A, et al. The influence of hip rotation on femoral offset in plain radiographs. Acta Orthop 2014;85(4):389-95. https://doi.org/10.3109/17453674.2014.931196.

10. Gum JL, Asher MA, Burton DC, et al. Transverse plane pelvic rotation in adolescent idiopathic scoliosis: primary or compensatory? Eur Spine J 2007;16(10):1579-86. https://doi.org/10.1007/s00586-007-0400-4.

11. Ghostine B, Sauret C, Assi A, et al. Influence of patient axial malpositioning on the trueness and precision of pelvic parameters obtained from 3D reconstructions based on biplanar radiographs. Eur Radiol 2017;27(3):1295-302. https://doi.org/10.1007/s00330-016-4452-x.

12. Sabourin M, Jolivet E, Miladi L, et al. Three-dimensional stereoradiographic modeling of rib cage before and after spinal growing rod procedures in early-onset scoliosis. Clin Biomech 2010;25(4):284-91. https://doi.org/10.1016/j.clinbiomech.2010.01.007.

13. Houston S, Zaleski W. The shape of vertebral bodies and femoral necks in relation to activity. Radiology 1967;89(1), https://doi.org/10.1148/ 89.1.59.

14. Chung CY, Lee KM, Park MS, et al. Validity and reliability of measuring femoral anteversion and neck-shaft angle in patients with cerebral palsy. J Bone Jt Surg 2010;92(5):1195. https://doi.org/10.2106/JBJS.I. 00688.

15. Wilson JD, Eardley W, Odak S, et al. To what degree is digital imaging reliable? Validation of femoral neck-shaft angle measurement in the era of picture archiving and communication systems. $\mathrm{Br} \mathrm{J}$ Radiol 2011;84(1000):375-9. https://doi.org/10.1259/bjr/29690721.

16. Mitton D, Deschenes S, Laporte S, et al. 3D reconstruction of the pelvis from bi-planar radiography. Comput Methods Biomech Biomed Engin 2006;9(1):1-5. https://doi.org/10.1080/10255840500521786.
17. Chaibi Y, Cresson T, Aubert B, et al. Fast 3D reconstruction of the lower limb using a parametric model and statistical inferences and clinical measurements calculation from biplanar X-rays. Comput Methods Biomech Biomed Engin 2012;15(5):457-66. https://doi.org/10.1080/ 10255842.2010.540758.

18. Quijano S, Serrurier A, Aubert B, et al. Three-dimensional reconstruction of the lower limb from biplanar calibrated radiographs. Med Eng Phys 2013;35(12):1703-12. https://doi.org/10.1016/j.medengphy.2013.07.002.

19. Bendaya S, Lazennec J-Y, Anglin C, et al. Healthy vs. osteoarthritic hips: a comparison of hip, pelvis and femoral parameters and relationships using the $\operatorname{EOS}^{\circledR}$ system. Clin Biomech 2015;30(2):195-204. https:// doi.org/10.1016/j.clinbiomech.2014.11.010.

20. Baudoin A, Skalli W, de Guise JA, et al. Parametric subject-specific model for in vivo 3D reconstruction using bi-planar X-rays: application to the upper femoral extremity. Med Biol Eng Comput 2008;46(8):799-805. https://doi.org/10.1007/s11517-008-0353-8.

21. Le Bras A, Laporte $\mathrm{S}$, Bousson $\mathrm{V}$, et al. 3D reconstruction of the proximal femur with low-dose digital stereoradiography. Comput Aided Surg 2004;9(3):51-7. https://doi.org/10.3109/10929080400018122.

22. Weir JPJ. Quantifying test-retest reliability using the intraclass correlation coefficient and the SEM. J Strength Cond Res 2005;19(1):231-40. https://doi.org/10.1519/15184.1.

23. Dunn G. Design and analysis of reliability studies. Stat Methods Med Res 1992;1(2):123-57. https://doi.org/10.1177/096228029200100202.

24. International Organization for Standardization ISO 5725-2. Basic method for the determination of repeatability and reproducibility of a standard measurement method. 1994.

25. Sangeux M, Pascoe J, Hons B, et al. Three-dimensional measurement of femoral neck anteversion and neck-shaft angle. J Comput Assist Tomogr 2015;39(1):83-5. https://doi.org/10.1097/RCT.0000000000000161.

26. Mast $\mathrm{NH}$, Impellizzeri F, Keller S, et al. Reliability and agreement of measures used in radiographic evaluation of the adult hip. Clin Orthop Relat Res 2011;469(1):188-99. https://doi.org/10.1007/s11999-0101447-9.

27. NS1 Broughton, Brougham DI, Cole WG, et al. Reliability of radiological measurements in the assessment of the child's hip. J Bone Jt Surg Br. 1989 Jan;71(1):6-8.

28. Casciaro ME, Ritacco LE, Milano F, et al. Angle estimation of human femora in a three-dimensional virtual environment. In: 2010 Annu int conf IEEE eng med biol soc EMBC'10, vol. 1; 2010. p. 3946-9. https:// doi.org/10.1109/IEMBS.2010.5627701.

29. Guenoun B, Zadegan F, Aim F, et al. Reliability of a new method for lower-extremity measurements based on stereoradiographic three-dimensional reconstruction. Orthop Traumatol Surg Res 2012; 98(5):506-13. https://doi.org/10.1016/j.otsr.2012.03.014.

30. Marmor M, Nystuen C, Ehemer N, et al. Accuracy of in situ neck-shaft angle and shortening measurements of the anatomically reduced, varus malreduced and shortened proximal femur: can we believe what we see on the postoperative films? Injury 2012;43(6):846-9. https:/l doi.org/10.1016/j.injury.2011.10.010.

31. Nelitz M, Guenther KP, Gunkel S, et al. Reliability of radiological measurements in the assessment of hip dysplasia in adults. Br J Radiol 1999;72(APR.):331-4. https://doi.org/10.1259/bjr.72.856.10474491.

32. Lequesne M, Malghem J, Dion E. The normal hip joint space: variations in width, shape, and architecture on 223 pelvic radiographs. Ann Rheum Dis 2004;63(9):1145-51. https://doi.org/10.1136/ard.2003.018424.

33. Olsen M, Davis ET, Gallie PAM, et al. The reliability of radiographic assessment of femoral neck-shaft and implant angulation in hip resurfacing arthroplasty. J Arthroplasty 2009;24(3):333-40. https:// doi.org/10.1016/j.arth.2008.01.304.

34. Martin Bland J, Altman D. Statistical methods for assessing agreement between two methods of clinical measurement. Lancet 1986;327(8476):307-10. https://doi.org/10.1016/S0140-6736(86)90837-8.

35. Zhang $\mathrm{Q}$ Liu $\mathrm{H}$, Chen $\mathrm{W}$, et al. Radiologic measurement of lesser trochanter and its clinical significance in Chinese. Skeletal Radial 2009;38(12):1175-81. https://doi.org/10.1007/s00256-009-0662-5. 